
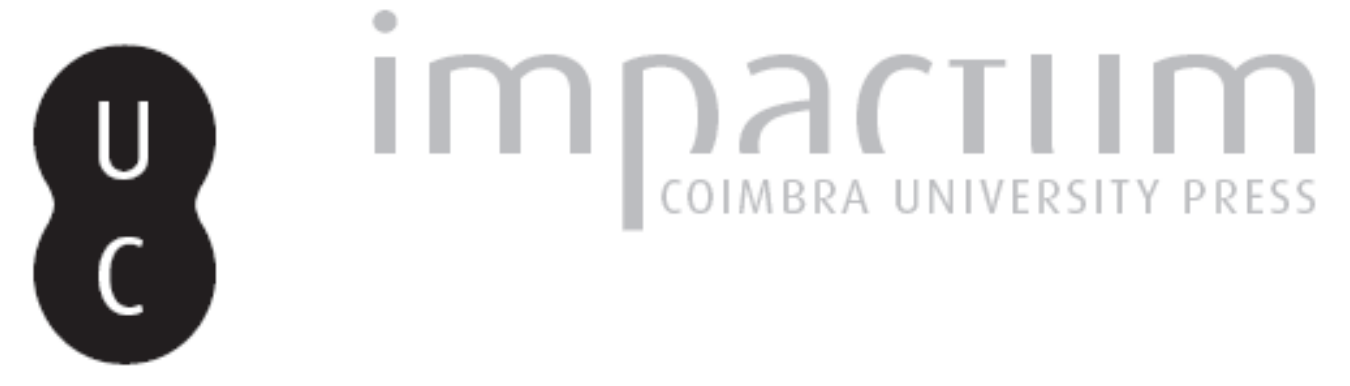

\title{
Futurismo, futurismos: de A Confissão de Lúcio a Nome de Guerra
}

\section{Autor(es): Costa, Paula Cristina}

Publicado por: Imprensa da Universidade de Coimbra

URL persistente:

URl:http://hdl.handle.net/10316.2/42578

DOI:

DOl:https://doi.org/10.14195/0870-8584_4_9

Accessed : $\quad$ 26-Apr-2023 07:28:33

A navegação consulta e descarregamento dos títulos inseridos nas Bibliotecas Digitais UC Digitalis, UC Pombalina e UC Impactum, pressupõem a aceitação plena e sem reservas dos Termos e Condições de Uso destas Bibliotecas Digitais, disponíveis em https://digitalis.uc.pt/pt-pt/termos.

Conforme exposto nos referidos Termos e Condições de Uso, o descarregamento de títulos de acesso restrito requer uma licença válida de autorização devendo o utilizador aceder ao(s) documento(s) a partir de um endereço de IP da instituição detentora da supramencionada licença.

Ao utilizador é apenas permitido o descarregamento para uso pessoal, pelo que o emprego do(s) título(s) descarregado(s) para outro fim, designadamente comercial, carece de autorização do respetivo autor ou editor da obra.

Na medida em que todas as obras da UC Digitalis se encontram protegidas pelo Código do Direito de Autor e Direitos Conexos e demais legislação aplicável, toda a cópia, parcial ou total, deste documento, nos casos em que é legalmente admitida, deverá conter ou fazer-se acompanhar por este aviso.

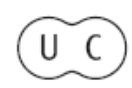




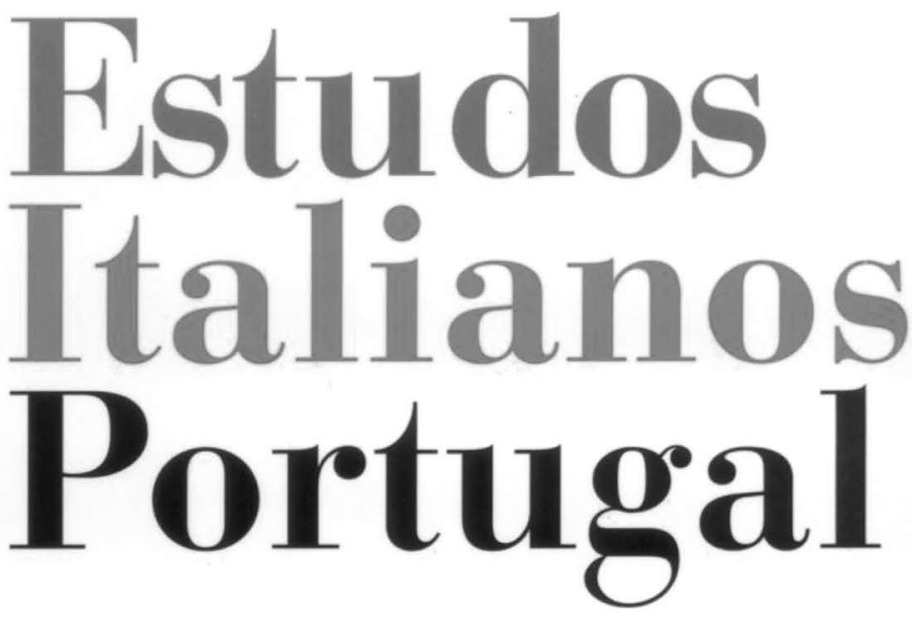

Instituto

Italiano

de Cultura

de Lisboa

Nova Série

$\mathbf{N}^{\mathbf{0}} 4$.

2009 


\title{
FUTURISMO, FUTURISMOS: DE $A$ CONFISSÃO DE LÚCIO A NOME DE GUERRA
}

\author{
Paula Cristina Costa*
}

Isto de ser moderno é como ser elegante: não é uma maneira de vestir mas sim um modo de ser.

Almada Negreiros

Como muitas das tentativas de periodização de qualquer movimento literário, as quais são por definição, dificeis e, por vezes mesmo frustrantes, tentar fazer a do futurismo em Portugal, também não é excepção. Se enquanto vanguarda, momento de apogeu e ruptura de valores, enquanto moda a seguir, ele é facilmente datável - de 1914 a 1918 -, coincidente com a primeira guerra mundial, enquanto atitude, modo de ser, ele é bastante mais dificil de arrumar cronologicamente. Desde 20 de Fevereiro de 1909, data da publicação do primeiro Manifesto Futurista de Marinetti, no Figaro, em Paris, e que, curiosamente, logo nessa data, o poeta açoriano Luís Francisco Bicudo ${ }^{1}$ nos surpreende ao dar-nos notícia

* Professora (Auxiliar) na FCSH da Universidade Nova de Lisboa (UNL), desde 1988;Licenciatura (1985), Mestrado (1990) e Doutoramento (2000) pela FCSH da UNL, nas áreas da Literatura Portuguesa Moderna e Contemporânea e da Literatura Comparada. Membro do Instituto de Estudos sobre o Modernismo (UNL) desde 1988. Publicou António Ramos Rosa, um poeta in fabula (Quasi, 2005), tem colaborado em várias revistas literárias, e escreveu verbetes para dicionários e enciclopédias da especialidade.

${ }^{1}$ Luís Francisco Bicudo (Ponta Delgada, 1884-1918), poeta e jornalista açoriano que se encontrava em Itália em 1909, e teve por isso o privilégio de conhecer Marinetti nessa altura e o acesso imediato ao seu Primeiro Manifesto do Futurismo de que logo nos dá notícia no Diário dos Açores; mais tarde, em Agosto, traduzi-lo-á para português e, juntamente com uma entrevista feita a Marinetti, voltará a falar do futurismo italiano no mesmo jornal açoriano onde 
em Portugal do seu aparecimento, passando pela crónica de Aquilino Ribeiro, publicada na Ilustração Portuguesa, em 1912, que falava do escândalo do sucesso de alguns pintores italianos futuristas, até à abertura oficinal do futurismo em Portugal, por Almada Negreiros, no Teatro República, a 14 Abril de 1917, nenhuma destas datas delimita, em absoluto, as fronteiras do futurismo português.

Efectivamente, se em Portugal só se fala com alguma segurança da presença do futurismo na nossa literatura, a partir da constituição da geração de Orpheu, entre 1914/15 e da publicação de textos como a "Ode Triunfal"2 e a "Ode Marítima"3 de Álvaro de Campos, "Poemas sem suporte" de Mário de Sá-Carneiro", "A Cena do Ódio" de Almada Negreiros 5 e até mesmo, "Chuva Oblíqua" 6 de Fernando Pessoa, a verdade é que já entre 1912/13 podemos encontrar manifestações de futurismo entre nós, quer na pintura, quer na literatura. Algumas das pinturas de Santa-Rita Pintor, datadas de 1912, já representavam amplamente os princípios deste ismo italiano; o mesmo se poderia dizer de Amadeo de Souza-Cardoso que teve o privilégio de chegar a Paris logo em 1906, no mesmo ano em que também chegaram Juan Gris, Modigliani e Severini e aí pôde ser cúmplice do nascimento da primeira vanguarda europeia do século XX. E, por isso mesmo, a pintura de Amadeo, muito cedo absorveu e recriou alguns dos princípios do futurismo, mesmo que ainda

colaborava assiduamente. Vide, Costa, Paula Cristina, "Bicudo, Luís Francisco Rebello", in Dicionário de Literatura Portuguesa (org. Álvaro Manuel Machado), Lisboa, Ed. Presença, 1996, p. 63.

2 Texto datado de 1914 e publicado em Março de 1915 no $1 .^{\circ}$ n. ${ }^{\circ}$ da revista Orpheu.

3 Texto publicado no 2. ${ }^{\circ}$ número da revista Orpheu, em 1915.

4 Textos datados de 1915 e publicados no mesmo ano no n. 2 de Orpheu.

5 Texto datado de 1915 e prevista a sua publicação para o $3 .^{\circ}$ n. ${ }^{\circ}$ da revista Orpheu o qual, como é sabido, nunca se chegou a concretizar. A Cena do Ódio só será publicada muito mais tarde, em 1923, na revista Contemporânea.

6 Texto datado de 8 Março 1914 e publicado no $2 .^{\circ}$ n. ${ }^{\circ}$ da revista Orpheu. 
pouco definíveis os contornos específicos face ao cubismo, ou a qualquer outro dos ismos desta vanguarda.

De 1913 é também o romance de Mário de Sá-Carneiro, $A$ Confissão de Lúcio, ficção que, ao ser analisada com alguma atenção nesta perspectiva, não poderá ser ignorada como marco fundamental para a compreensão da presença do futurismo na nossa literatura, ainda antes da entrada, por assim dizer oficial, do modernismo português, em 1915, com a publicação da revista Orpheu. Para além de outros indícios de futurismo já passíveis de serem encontrados nesta narrativa, um dos mais evidentes é o da presença do escultor Gervásio Vila-Nova que, por si só, revela bem o conhecimento que Mário de Sá-Carneiro já tinha, à data, de movimentos como o futurismo. O Selvagismo, ismo a que o artista aderira, recentemente, "pseudo-escola literária da última hora", cuja "novidade residia em os seus livros serem impressos sobre diversos papéis e com tintas de várias cores, numa estrambótica disposição tipográfica" , não pode negar as afinidades com alguns dos recém criados movimentos da vanguarda, nomeadamente, com a do futurismo italiano:

Também - e eis o que mais entusiasmava o meu amigo - os poetas e prosadores selvagens, abolindo a ideia, "esse escarro", traduziam as suas emoções unicamente em jogo silábico, por onomatopeias raspadas, bizarras: criando mesmo novas palavras que coisa alguma significavam e cuja beleza, segundo eles, residia justamente em não significarem coisa alguma ...De resto, até aí, parece que apenas se publicara um livro dessa escola. Certo poeta russo de nome arrevesado. Livro que Gervásio seguramente não lera, mas que todavia se não cansava de exalçar, gritando-o assombroso, genial... ${ }^{8}$

7 Sá-Carneiro, A Confissão de Lúcio, (Ed. Fernando Cabral Martins), Lisboa, Ed. Assírio \& Alvim, 1998, p. 18.

8 Ib., pp. 18-9. 
A caracterização fictícia deste selvagismo que Mário de Sá-Carneiro faz pela voz de Gervásio Vila-Nova, revela o conhecimento que este poeta já tinha do cubismo e do futurismo, desde muito cedo, apesar de se perceber ainda uma certa indefinição entre estes ismos. Revela também que já em 1913, não tinha ficado indiferente ao futurismo e ao formalismo russo, já que esse poeta russo de nome arrevesado, terá grandes probabilidades de poder ter sido inspirado no poeta Maiakovsky. Revela ainda, o conhecimento, se bem que provavelmente ainda muito incipiente e confuso de uma outra grande quantidade de ismos que por toda a Europa brotavam, na literatura e na pintura, desde o Fauvismo até ao Expressionismo alemão. A convivência de Sá-Carneiro em Paris com Picasso, Braque, Apollinaire, o casal Delaunay, entre outros poetas e artistas que também aí se encontravam, será fundamental ao poeta de Quasi, quer para uma abertura da sua própria poética a esses novos ismos, quer para Fernando Pessoa que, através da correspondência assídua trocada com Sá-Carneiro, também se vai informando e deixando entusiasmar pelas novidades vanguardistas. É conhecida a importância que Sá-Carneiro teve como mediador nesta aproximação, à distância, de Pessoa, relativamente ao cubismo e ao futurismo e a consequente cumplicidade poética alimentada por ambos, na criação dos ismos de Orpheu - paulismo, interseccionismo, sensacionismo. E também é possível acompanhar, lendo esta correspondência, o percurso de aprendizagem por parte de Sá-Carneiro, destas novas tendências ísmicas: desde uma inicial desconfiança em relação ao cubismo até a um cada vez maior entusiasmo relativamente ao futurismo, sobretudo pela voz do então recentemente criado Álvaro de Campos que foi logo por si considerado e elogiado como autor da "obra-prima do Futurismo. Porque, apesar talvez de não pura, escolarmente futurista - o conjunto da ode é absolutamente futurista" .

9 Em carta datada de 20.6.1914. in Cartas de Mário de Sá-Carneiro a Fernando Pessoa, (Ed. Manuela Parreira da Silva), Lisboa, Assírio \& Alvim, 2001, p. 108. 
Mas voltemos à Confissão de Lúcio. Gervásio Vila-Nova, o escultor selvagista que presentifica nesta narrativa o conhecimento de Sá-Carneiro por estes ismos europeus da vanguarda do início do século XX, ficcionaliza igualmente a desconfiança que é conhecida de Sá-Carneiro relativamente à verdadeira credibilidade destes ismos. Já foi apontado o paralelismo entre este escultor selvagista e Santa-Rita Pintor ${ }^{10}$, a quem o nosso poeta, pelo menos à época, parecia não levar muito a sério e não concordar com a sua atitude demasiado exibicionista, muito blagueur $^{11}$. Se bem que esta identificação reforce a insegurança ainda sentida por Sá-Carneiro face ao cubismo e ao futurismo, igualmente transposta para a criação de Manuel Lopes, "o pintor cretino" 12 cubista, personagem de alguns dos seus contos reunidos em Céu em Fogo, a verdade é que estas personagens são já a voz de uma vanguarda que vai, a pouco e pouco, preparando e ocupando o seu espaço e os seus lugares de sentido na obra ficcional de Sá-Carneiro.

O mesmo se poderia dizer de outros elementos desta ficção que podem igualmente ser considerados como o início de um ciclo vanguardista que já aqui se faz prever e adivinhar, apesar de ainda muito equilibrado com toda uma poética herdeira da tradição simbolista, paúlica e mesmo neo-romântica de Sá-Carneiro. E apesar do seu futurismo ser ainda neste momento (e talvez mesmo sempre) "um Futurismo de atitude ou até de moda", como já foi referido por Fernando Cabral Martins ${ }^{13}$, a verdade é que aspectos como a exalta-

${ }_{10}$ Paula Cristina L. Costa C., As Dimensões artísticas e literárias do projecto sensacionista, Dissertação de Mestrado apresentada à FCSH da UNL, 1990, pp. 66-69.

11 Em carta datada de 10 Maio de 1913, in Cartas de Mário de Sá-Carneiro a Fernando Pessoa, cit., pp. 84-5.

12 Sá-Carneiro, "Ressurreição", in Céu em Fogo, (Ed. Fernando Cabral Martins), Lisboa, Assírio \& Alvim, 1999, p. 222.

13 Fernando Cabral Martins, "Os vasos comunicantes”, Posfácio a A Confissão de Lúcio, (Ed. Fernando Cabral Martins), Lisboa, Assírio \& Alvim, 1998, p. 137. 
ção da cidade na sua "actividade febril contemporânea"14, "a assunção da beleza do efémero, do veloz"15, a exaltação da luxúria e da perversidade, são alguns dos topoi que permitem situar esta narrativa nos primórdios do futurismo em Portugal. Mesmo que esse pré-futurismo, por assim dizer, esteja ainda muito colado à poética de Baudelaire e se manifeste essencialmente como uma confluência da modernidade já prosseguida pelo poeta de albatroz com o início do modernismo a que Sá-Carneiro assiste e pelo qual se deixa seduzir.

Efectivamente, episódios como a descrição do espectáculo da Orgia do fogo da americana sáfica na narrativa $A$ Confissão de Lúcio, se podem ser lidos à luz da herança de uma poética simbolista ${ }^{16}$, recriando os mitos quer de Salomé quer de Ofélia, e sugestionando pela sua leitura um cenário sinestésico de múltiplas e vertiginosas correspondências, os mesmos episódios podem também já abrir-se a uma outra leitura mais ousadamente vanguardista, onde alguns dos princípios futuristas já marcam presença: a exaltação da luz eléctrica, o "turbilhão meteórico" das "torrentes luminosas", "uma música penetrante que tilintava nessa nova aurora, em ritmos desconhecidos"17, o vertiginismo e o êxtase das sensações, a perversão aclamada pelas bailarinas lésbicas, e todo um cenário "requintado d’ultra-civilização e arte"18 em que toda a voluptuosidade era regra a seguir.

Num sentido mais lato, a questão central do núcleo desta narrativa, nomeadamente a de uma poética da alteridade, da cisão dramática entre o eu e o outro que o poeta de Quasi já tinha desenvolvido exaustivamente na sua poesia, e vemos ser reescrita em $A$ Confissão de Lúcio através do triângulo Lúcio/Ricardo/Marta, revela já uma das prioridades do

14 Sá-Carneiro, in A Confissão de Lúcio, op. cit., p. 45.

$15 \mathrm{Ib}$.

16 Fernando Cabral Martins, in op. cit., p. 137.

17 Sá-Carneiro, in A Confissão de Lúcio, op. cit., p. 29.

18 Ib., p. 29. 
modernismo: a de uma poética da dispersão do eu que, num permanente movimento de queda e de ascensão, persegue insistentemente o ideal de um outro mais belo e mais perfeito. Na obra de Sá-Carneiro, poesia e prosa, esta dilaceração entre o eu e o outro conduz frequentemente a uma identificação do eu com máscaras, personagens cómico-dramáticas, facilmente integráveis numa tradição simbolista e decadente: "o esfinge gorda", "o papa-açorda", "Rei-lua postiço", "bobo presunçoso"19, são algumas das mais conhecidas; paradoxalmente, o outro coloca sempre a máscara de um eu que, para além de mais perfeito e de não sofrer da patologia do spleen de fim de século, é também por isso um eu mais moderno, a la page das últimas tendências vanguardistas, facilmente entusiasmável pelas recentes descobertas da arte, em geral, e mesmo pelas da ciência. Na novela "Asas", escrita em 1912, a presença do artista russo Petrus Ivanowitch Zagoriansky, revela bem o fascínio sentido por uma nova concepção de arte, projectada pelo narrador na voz-outra desta personagem já quasi futurista:

E nas grandes oficinas ... o giro ácido das rodas ... os volantes ... os êmbolos ... as correias de transmissão ... o oscilar de complicados maquinismos ... Outros tantos movimentos de ar - fogos de artificio, é verdade, fogos de artificio de Ar!... Hélices, espirais, ramos de parábola, estrelas, hipérboles mortas - turbilhonando, zigue-zagueando, entregolfando-se ... Magia contemporânea! Europa! Europa! ... ${ }^{20}$

Ora esta concepção trágica do eu, esta ambivalência entre a nostalgia de um passado de áureos templos de ritos de cetim ${ }^{21}$,

19 Sá-Carneiro, "Aquele Outro", in Poemas Completos, (Ed. Fernando Cabral Martins), Lisboa, Assírio \& Alvim, 1996, p. 141.

${ }^{20}$ Sá-Carneiro, "Asas", in Céu em Fogo, (Ed. Fernando Cabral Martins), Lisboa, Assírio \& Alvim, 1999, p. 119

21 Sá-Carneiro, "Distante Melodia”, in Poemas Completos, cit., p. 85. 
projectado na imagem de um eu saudosista, decadente e passadista, alternando com a criação de um outro, ávido de Europa e de uma nova arte que se projecte mais além no futuro, estas duas faces de Janus que se sobrepõem na auto-construção do eu, presentes na obra poética de Sá-Carneiro pelo menos desde 1912/13, revelam bem este interseccionismo entre uma atitude romântico-simbolista e a voz da vanguarda modernista que já se começa a fazer sentir. Revela, inclusivé, a encenação de uma mente futurista, na tentativa idealizada de uma passagem do herói trágico romântico para o herói, não menos trágico, mas modernista, que acredita num ressurgimento do eu no futuro, num porvir mais despersonalizado, mais mecanicamente multiplicado por si próprio em super-eus em luta por uma unidade mais dinâmica.

Tomando como exemplo apenas estes dois romances - A Confissão de Lúcio e Nome de Guerra - podemos repensar as fronteiras do futurismo em Portugal. Na obra de Mário de Sá-Carneiro, parece difícil apontar como exemplos únicos da sua adesão efémera e temporária ao ismo de Marinetti, alguma da sua poesia datada entre 1914/15, nomeadamente textos como "Manucure" ou "16". Efectivamente, quer a narrativa $A$ Confissão de Lúcio (1913) quer alguns dos contos reunidos em Céu em Fogo (datados entre 1913/14) denotam já, não só o conhecimento que Sá-Carneiro tinha à data do cubismo e do futurismo, como também o aproveitamento de alguns dos seus princípios para a criação de personagens que lhes dêem voz e, sobretudo, como pretexto para uma reflexão em torno dos novos caminhos, trilhados pela vanguarda europeia, da literatura em diálogo com as artes plásticas.

Também a obra poética de Almada Negreiros nos faz rever as fronteiras movediças de uma cronologia do futurismo em Portugal. Em Almada, o mais novo ${ }^{22}$ dos artistas de Orpheu,

22 Almada Negreiros nasceu em 1893, em S. Tomé, por isso mais novo 5 anos do que Pessoa e mais novo 3 do que Sá-Carneiro. 
à época a viver em Portugal, por isso sem ter tido oportunidade de conviver em Paris com outros artistas da vanguarda, o futurismo parece avançar pela sua obra sobretudo a partir de textos como A Cena do Odio (1915), Saltimbancos (1916), A Engomadeira (1915), Manifesto Anti-Dantas (1915) e, mais tarde, K4 O Quadrado Azul (1917), Mima-Fataxa (1917), culminando esta sua euforia futurista com a apresentação da $1 .{ }^{a}$ Conferência Futurista e do Ultimatum Futurista às gerações portuguesas do século XX (1917). De facto, é entre 1915/1917 que podemos situar a fase mais marcadamente interventiva $\mathrm{e}$ entusiasta de Almada Negreiros pelo futurismo, como aliás, a de outros modernistas portugueses, como Pessoa-Campos. Para Almada, será a sua fase do ex-libris do pecado, do poeta que recria e intensifica o satanismo de Baudelaire, dando-lhe contornos muito mais violentos e perversos, como se pode constatar pela leitura do poema-manifesto $A$ Cena do Ódio. Efectivamente, se a algum dos poetas de Orpheu assenta bem o epíteto de futurista, será certamente a Almada. Todos os textos supra-citados são verdadeiras obras-primas do futurismo português e, alguns deles, vão mesmo mais além, e antecipam, em alguns aspectos, o próprio surrealismo: Saltimbancos e A Engomadeira.

Entre finais de 1917, princípios de 1918, coincidindo com a proibição da revista Portugal Futurista (1917), com a morte de Amadeo de Souza-Cardoso e de Santa-Rita Pintor (1918), e já dois anos antes, com o suicídio de Mário Sá-Carneiro, para além do fim da 1. ${ }^{a}$ Guerra Mundial, o grupo de Orpheu dispersa-se, desagrega-se e a aposta futurista parece, em Portugal, como aliás noutros países europeus, perder a sua força de vanguarda e diluir-se noutros projectos mais individualizados. Almada Negreiros, partirá para Paris, em 1919, e aí permanecerá durante ano e meio, onde irá conhecer Max Jacob, Picabia, Brancusi e outros artistas que irão ter influência na mudança radical a que assistimos na sua obra durante esse período parisiense. Um 
certo primitivismo, que já se vinha a desenhar na sua obra desde o contacto em Portugal com Larionov ${ }^{23}$ desencadeia-se numa poética da ingenuidade, que textos escritos entre 1919/1921, tais como, Histoire du Portugal par coeur (1919), A Invenção do Dia Claro (1921) e o Kágado (1921), muito bem revelam.

Mas se, de facto, o futurismo parece estar adormecido em Almada no início da década de 20, o seu romance Nome de Guerra, escrito em 1925 (apesar de só publicado em 1938), rapidamente nos faz mudar de opinião. Quando comparado com o estilo de textos como os já citados, $A$ Cena do Ódio, A Engomadeira, Saltimbancos, K4 O Quadrado Azul, entre outros, o romance em nada se assemelha a esse registo de linguagem futurista, a essas experimentações analógicas e oníricas. Pelo contrário, Nome de Guerra, apresenta-se num estilo sóbrio, neutro, reflexivo, apesar da enorme novidade, sobretudo a nível estrutural que apresenta. Quanto ao tema, o romance também não é, aparentemente, muito inovador: trata-se da história de Luís Antunes, um rapaz provinciano que aos trintas anos, vem para a cidade ${ }^{24}$ a mando dum tio que quer fazer dele um homem, e na boémia da noite lisboeta dos anos 20 , se perde de amores por uma prostituta, de nome Judite, que o salvará do anacronismo da relação com Maria, a rapariga com quem a sua família esperaria que ele um dia viesse a casar. Tendo como mediadores do seu processo de aprendizagem e de autodiagnóstico, Judite e a vida citadina, Luís Antunes deixará de existir apenas, para passar a viver e, na vertigem do movimento das novas emoções sentidas e experimentadas, encontrar-se-á consigo mesmo, à medida que se vai con-

23 Colaborador da companhia dos Bailados Russos de Diaghilev representados em Lisboa entre Dezembro de 1917 e Janeiro de 1918

${ }^{24}$ Como é sabido, já romances como A Capital de Eça de Queirós ou Pântano de João Gaspar Simões, entre outros, se centraram neste tema da cidade como mediadora da aprendizagem da vida feita pelo protagonista. 
seguindo libertar e exorcizar do mal que os outros - a família, a sociedade - lhe fizeram. Neste sentido, mais importante do que o contar da história, são todas as reflexões filosóficas que acompanham a transformação desta personagem e que situam este romance-ensaio numa linhagem de outros romances, tais como, entre nós, Elói ou romance numa cabeça, de João Gaspar Simões (1932), por exemplo, ou à escala universal, romances como, Ulisses, de Joyce (1914-21), ou ainda no limite, O homem sem qualidades de Musil (1930-42).

E quanto ao futurismo? Onde estão as suas marcas neste romance de Almada? Na sequência do que já foi dito, na exaltação da cidade e das grandes multidões; na exaltação do automóvel e da velocidade. Muitos são os capítulos de Nome de Guerra em que a viagem de automóvel é cantada e a velocidade do motor convida à euforia de algumas das personagens:

Como se fizessem parte do motor, as três companheiras da Judite iam sempre a falar e acompanhavam com as suas vozes a velocidade do carro. Quando a velocidade lhes dava a ilusão de irem de avião, era tão aguda a gritaria como as das buzinas navais a quererem vencer a distância. ${ }^{25}$

Sem dúvida que o fascínio pelo automóvel e pela velocidade marcará toda uma geração de escritores que publicam nas décadas de 20/30, tais como, por exemplo, F. Scott Fitzgerald, em O Grande Gatsby (1925) ou Alberto Moravia, em Os Indiferentes (1929), dois romances pós-futuristas datados da mesma década de Nome de Guerra e onde este topos se desenvolve e renova à luz de uma era mecânica em expansão, do sonho da construção de uma sociedade urbana moderna e, consequentemente, de uma burguesia

25 In Nome de Guerra, cit., p. 115. 
que começa a dar sinais do gosto pela ostentação e pelo luxo, pelo vazio e pela indiferença face a valores não materiais. Tal se verifica, em particular no romance de Almada Negreiros, onde para D. Jorge (o experimentado que tem a seu cargo fazer de Luís Antunes um Homem), para Judite e para as outras raparigas do clube, viajar de automóvel revela não só o prazer pela velocidade e pela ilusão de irem de avião e vencerem as distâncias mas, também o gosto pela exibição de um estatuto social, aparentemente, superior e ultra-civilizado.

O futurismo marca ainda presença em Nome de Guerra pela exaltação da guerra, agora já não a bélica, como a única higiene dos povos, mas uma guerra interior, aqui presentificada por Judite, o nome de guerra que irá servir de pedra de toque no despertar para a descoberta de si mesmo, em Luís Antunes. Neste sentido, presenciamos algumas cenas de violência, praticadas sobretudo por D. Jorge, homem bruto e ordinário, que despreza, trata mal as papillons do clube e que, parece seguir ainda os preceitos marinettenianos, quando à eficácia da bofetada e do soco $^{26}$, para querer convencer os outros da sua imensa virilidade:

A Judite deu uma gargalhada que lhe fez cair a cabeça para trás. Mas o experimentado, vendo que por aquela forma a noite se lhe ia por "água abaixo", recorreu ao absurdo de uma valente bofetada na pobre rapariga que fazia de número quatro. ${ }^{27}$

Mas é sobretudo na exaltação de uma beleza não-aristotélica que os ecos do futurismo se fazem ouvir com uma grande nitidez em Nome de Guerra. A descrição fisica de Judite, como uma Vénus de Milo mutilada, feia e grotesca até, com os seus

26 Marinetti, Primeiro Manifesto do Futurismo, in Antologia do Futurismo Italiano - Manifestos e poemas (organização, tradução, introdução e notas de José Mendes Ferreira), Lisboa, Vega, 1979, p. 49

27 In Nome de Guerra, cit.,p. 27. 
seios hediondos, nádegas de rapaz, pernas saltimbancanescas, joethos estropiados, pés horríveis, é bem sintomática do olhar sobre si de Luís Antunes, já não como um homem apaixonado, mas como um homem a quem a Judite estava a passar-lhe, por isso a conseguir vê-la sob a luz crua e desencantada da realidade daquele corpo. Mas é também toda esta descrição plástica do corpo de Judite, uma verdadeira manifestação do aproveitamento de um novo conceito de belo que, desde Baudelaire, prossegue em pleno cubismo e futurismo, como, e paradoxalmente, o culto do feio, do horror, do grotesco. Assim, e se para os futuristas, um automóvel de corridas (...) é mais belo do que a Vitória de Samotrácia ${ }^{28}$, o modo como Judite nos é descrita, revela bem essa violência da inversão do belo, essa nova concepção da obra de arte que se deseja, não na harmonia clássica das suas formas e linhas, mas mutilada pela desconstrução e pelo desassossego da sua matéria:

Se a Judite fosse uma estátua, podia ser aproveitada como exemplo de beleza depois de sofrer algumas mutilações. Estas seriam correspondentes aos estragos que a vida fizera sobre aquela natureza formosa e robusta. Por exemplo: destruir-lhe os seios. Não cortá-los: destruí-los completamente e deixar-lhes os vestígios de terem sido retirados. Cortar-lhe os braços como os da Vénus de Milo, isto é, conservando apenas a capa dos ombros e os sovacos.

Aproveitar-lhe da cabeça tanto quanto possível apenas o perfil e não deixar continuar as costas desde as omoplatas para cima ${ }^{29}$.

Efectivamente, muitos são os ecos do futurismo ainda presentes em Nome de Guerra. Se pelo estilo, Almada se afasta já dos experimentalismos da escola de Marinetti, pela atitude, ele mantém-se fiel a muitos dos seus princípios. O texto já

\footnotetext{
28 Marinetti, in op. cit., p. 49.

29 In Nome de Guerra, cit., p. 101.
} 
não é entendido como uma performance, como a encenação de um eu futurista, mas a atitude mantém-se: Luís Antunes é o herói futurista que luta contra todo o passadismo da sua vida anterior, institucional, que se quer desenvencilhar do anacronismo de uma família, de uma namorada, de uma sociedade e que na turbulência da cidade, se salva do provincianismo também de um amor como obsessão romântica e ganha o amor ao perigo, à coragem, à revolta e à audácia de viver a sua própria vida, sem mestres, apenas na sensação dinâmica da sua independência e da sua liberdade.

Tomando como fronteira estes dois romances, $A$ Confissão de Lúcio e Nome de Guerra, podemos concordar com José-Augusto França, quando afirma que:

O Nome de Guerra está para o fim da geração do Orpheu como A Confissão de Lúcio, de Sá-Carneiro (1913), está para o seu princípio - romances de ambiente, histórias "mentais" da personalidade que se aniquila ou se cria. ${ }^{30}$

Poder-se-ia ainda acrescentar que a leitura conjunta destes dois romances, tão diferentes no tempo quanto no modo, nos ajuda não só a melhor compreender o que aproxima e o que afasta o princípio e o fim da geração de orpheu, mas também, consequentemente, nos fazem repensar a diferença entre futurismo e futurismos. Assim, se o futurismo é a vanguarda efémera e temporal, delimitável cronologicamente entre 1914/1915 e 1917/1918, se ele é a moda a seguir euforicamente durante um determinado período, os futurismos estão para além da vanguarda, eternos e atemporais, por isso, não datáveis: eles são o modo, a atitude que antecipa ou perdura para além do epicen-

30 José Augusto França, A Arte em Portugal no século XX, 1911-1961, Lisboa, Livros Horizonte, $4^{\text {a }}$ Ed., 2009, p. 98 
tro do vulcão em actividade da vanguarda; lava arrefecida que calcifica e faz perdurar princípios que se assimilaram e incorporaram e que não se apagam com o tempo, estando sempre prontos a serem reactivados em qualquer outra vanguarda seguinte.

Almada Negreiros é um bom exemplo desta passagem do futurismo aos futurismos: depois do fulgor e da euforia com que viveu o futurismo, pisando o fogo do vulcão desta vanguarda com mais paixão do que qualquer outro autor do modernismo português, seguiu-se um arrefecimento gradual deste fogo sem, contudo, deixar apagar as marcas da lava que se espalharam por toda a sua obra posterior. E aí abriram novas clareiras de sentido, novos caminhos para novas vanguardas - a do surrealismo, que já se adivinhava, há muito, na sua poética (Saltimbancos, A Engomadeira) e que irá ter, mais tarde, uma continuidade renovada no seu teatro que começará a escrever, durante a sua estadia em Madrid, na cumplicidade de F. García Lorca, entre 1927-1932.

Precisamente, em 1932 (já Almada tinha regressado a Portugal), Marinetti vem a Lisboa, numa tentativa frustrada de reabilitação do futurismo, fazendo-se anacronicamente acompanhar por Júlio Dantas e por António Ferro. É, então, que Almada se demarca, claramente, deste Marinetti II $^{31}$, como lhe chamou, o académico e fáscio italiano ${ }^{32}$ apoiante de Mussolini, personagem que já não lhe merece nenhuma admiração ou respeito, por oposição ao Primeiro Marinetti, o grande revolucionário da arte, esse sim, aquele com o qual ele, em tempos, se identificou. Esta sua posição face a Marinetti, só reforça a sua verdadeira atitude futurista: a de anti-aca-

31 Almada Negreiros, "Uma resposta - o cheiro a bafio e várias outras singularidades", in Obras Completas - Textos de Intervenção, Lisboa, INCM, vol. VI, 1993, p. 132.

32 Almada Negreiros, in "Um ponto no I do futurismo", in Obras Completas, cit., p. 92. 
démico, combativo, irreverente, a de um português sem mestre que prosseguirá sempre o seu caminho independente, de combate da subordinação da arte à política, de luta pela defesa do indivíduo à despersonalização das grandes massas.

Ficaria assim reforçada a coerência da sua atitude: para Almada Negreiros ser moderno e, particularmente, ser futurista, não foi apenas uma maneira de vestir - foi sempre o seu verdadeiro modo de ser. 